\title{
ÉPOCAS DE APLICAÇÃO DE GESSO AGRÍCOLA NA CULTURA DO AMENDOIM (Arachis hypogaea L.)
}

\author{
Ruan Aparecido Biagi Betiol ${ }^{1}$; Godofredo Cesar Vitti Vitti²; Eduardo Zavaschi ${ }^{3}$
}

${ }^{1}$ Graduando em Engenharia Agronômica, ESALQ/USP, Piracicaba, SP, ruanbetio197@gmail.com; ${ }^{2}$ Professor sênior do departamento de Ciência do Solo, ESALQ/USP, Piracicaba, SP; ${ }^{3}$ Doutor em Solos e nutrição de plantas, consultor agronômico pela empresa Vittagro.

RESUMO: O objetivo do estudo foi avaliar o efeito da época de aplicação de 1 ton ha $^{-1}$ de gesso agrícola na produtividade da cultura do amendoim. O delineamento experimental foi inteiramente casualizado com 3 tratamentos e 5 repetições. Os tratamentos consistiram da aplicação de 1 ton ha ${ }^{-1}$ de gesso agrícola no pré-plantio incorporado ao solo, 1 ton $\mathrm{ha}^{-1}$ em cobertura no momento de florescimento da cultura, e $0,5 \mathrm{t} \mathrm{ha}^{-1}$ incorporada ao solo no pré-plantio $+0,5$ ton ha ${ }^{-1}$ em cobertura no momento do florescimento. A aplicação de gesso agrícola em diferentes épocas não teve efeito na produtividade de grãos da cultura do amendoim.

Palavras-chave: amendoim, gesso agrícola, cálcio, época de aplicação.

\section{INTRODUÇÃO}

A cultura do amendoim é uma das mais exigentes em cálcio, extraindo de 113 a $200 \mathrm{~kg} \mathrm{ha}^{-1} \mathrm{de}$ Ca (SICHMANN; NEPTUNE; SABINO, 1970). O cálcio promove casca firme e sadia, diminui vagens sem grãos, melhora a formação dos frutos, promove maior fertilidade das flores, aumenta o crescimento das raízes e reduz a ocorrência de doenças causadoras de podridões de raiz. (VITTI et al., 2008). O íon $\mathrm{Ca}^{++}$é passivamente absorvido (fluxo de massa) pelo sistema radicular sendo transportado por meio do xilema até a parte aérea, portanto, a absorção depende da concentração no solo e da corrente transpiratória. Todavia, como esse elemento praticamente não se transloca via floema, não ocorre redistribuição do Ca para os frutos e sementes, sendo então necessária a absorção direta da solução do solo pelos órgãos reprodutivos (ginóforos, cascas e vagens do amendoim). (BOLONHEZI; GODOY; SANTOS, 2013).

Uma forma eficiente, e com baixo custo de fornecer Ca é a utilização do gesso agrícola. Segundo VITTI et al. (2008), o uso do gesso possibilita o aumento do teor de cálcio no solo e diminuição da saturação por alumínio, o que favorece maior crescimento radicular, resultando em exploração de maior volume de solo, tornando a planta mais resistente a situações de déficit hídrico, sendo capaz de aproveitar melhor os nutrientes provenientes do solo e dos fertilizantes. Ademais, o gesso é fonte do macronutriente enxofre, o qual participa do processo de fixação de nitrogênio atmosférico, além de estar presentes em enzimas, vitaminas e aminoácidos essenciais. 
Desta forma, em função dos benefícios apresentados pelo uso do gesso no amendoim, é extremamente viável a aplicação deste insumo na cultura, porém há a necessidade de verificar qual a melhor época da aplicação do produto na oleaginosa.

O objetivo do estudo foi avaliar o efeito da época de aplicação de 1 ton ha ${ }^{-1}$ de gesso agrícola na produtividade da cultura do amendoim.

\section{MATERIAL E MÉTODOS}

O experimento foi desenvolvido em área de reforma de cana-de-açúcar no município de JaúSP, com latitude $22^{\circ} 17^{\prime} 44^{\prime \prime}$ sul e longitude $48^{\circ} 33^{\prime} 28^{\prime \prime}$ oeste, a 541 metros de altitude. O amendoim foi cultivado no sistema convencional, onde a soqueira do canavial foi destruída e incorporada ao solo por meio de sucessivas gradagens até condições ideais para o plantio. O solo da área experimental é classificado como Argissolo Vermelho Amarelo distrófico típico, de textura média. O clima na região é classificado como Cfa, segundo Köppen. A pluviosidade média é de $1277 \mathrm{~mm}$.

O delineamento experimental foi inteiramente casualizado com 3 tratamentos e 5 repetições.

Os tratamentos consistiram na aplicação de 1 ton ha ${ }^{-1}$ da cultura do amendoim em cobertura, pré-plantio e pré-plantio + cobertura (Tabela 1). Cada parcela possuia 9 metros de largura, com 10 (dez) linhas de plantio de espaçamento 0,90 m (8 linhas centrais como parcela útil), 10 metros de comprimento e um estande médio de 12 plantas por metro. A primeira aplicação de gesso ocorreu em área total no pré-plantio, quando houve o preparo de solo (17/09/16), sendo incorporado ao solo por grade intermediária. A segunda foi na cobertura em área total no início do florescimento (10/12/16), aos quarenta e oito dias após o plantio da cultura.

Tabela 1. Descrição dos tratamentos.

\begin{tabular}{ccc}
\hline Tratamento & Épocas & Dose de gesso / aplicação (ton ha ${ }^{-1}$ ) \\
\hline GC & Início do florescimento & 1,0 \\
GP & Pré-Plantio & 1,0 \\
GPC & Pré-Plantio + Início do florescimento & $0,5+0,5$ \\
\hline
\end{tabular}

$\mathrm{GC}$ - gesso aplicado em cobertura $\left(1\right.$ ton $\left.\mathrm{ha}^{-1}\right) ; \mathrm{GP}$ - gesso aplicado em pré-plantio (1 ton ha $\left.{ }^{-1}\right) ; \mathrm{GPC}-$ gesso aplicado em pré-plantio $\left(0,5\right.$ ton ha $\left.{ }^{-1}\right)$ e em cobertura $\left(0,5\right.$ ton ha $\left.{ }^{-1}\right)$.

A cultivar de amendoim utilizada foi a IAC-OL3, pertencente ao grupo Virgínia ou Runner, a qual possui hábito de crescimento rasteiro. O ciclo da cultivar é, em média, de 130 dias, e a produtividade esperada é de $4.500 \mathrm{~kg} \mathrm{ha}^{-1}$, sendo que o seu potencial produtivo pode ultrapassar 7.000 $\mathrm{kg} \mathrm{ha}^{-1}$.

O plantio foi realizado em 23/10/2016 (36 dias após a primeira aplicação de gesso) e o arranquio foi em 21/02/2017 (157 dias após a primeira e 73 dias após a segunda aplicação de gesso). A 
colheita da área experimental ocorreu em 27/02/2017, momento em que os grãos apresentavam $11 \%$ de umidade.

Para a correção do solo, para o cultivo da cana-de-açúcar, foi amostrado e analisado o solo nas profundidades de 0-20 e 20-40 cm, e realizado a recomendação da calagem pelo critério do V\%. A aplicação de calcário ocorreu em pré-plantio incorporado ao solo. Após esse manejo, fez-se a adubação mineral localizada no sulco de plantio da cultura do amendoim com 10, 75 e $25 \mathrm{~kg} \mathrm{ha}^{-1}$ de N, $\mathrm{P}_{2} \mathrm{O}_{5}$ e $\mathrm{K}_{2} \mathrm{O}$, respectivamente. Houve também a aplicação de boro, na dose de $0,5 \mathrm{~kg} \mathrm{ha}^{-1}$, via solo, em área total, na pré-emergência da cultura do amendoim.

As avaliações realizadas no experimento foram:

a) Diagnose foliar: Foram analisadas as folhas do ápice das plantas trinta (30) dias após a aplicação de gesso em cobertura. A análise foliar foi realizada de acordo com Malavolta; Vitti; Oliveira (1997).

b) Contagem de vagens e grãos: Contagem do total de vagens e grãos por planta. Contaram-se as vagens e grãos de cinco (5) plantas de cada parcela.

c) Produtividade de grãos: Colheu-se com auxílio de colhedora mecanizada as vagens das plantas localizadas nas 8 linhas centrais. A massa dos grãos foi corrigida considerando teor de água de $11 \%$.

d) Peso de 100 grãos e 20 vagens: Contagem e pesagem de 100 grãos e 20 vagens, cuja massa foi corrigida considerando teor de água de $11 \%$.

e) Amostragem de solo: Amostragem do solo nas profundidades de 0-20 cm e 20-40 cm após a colheita da cultura.

Os resultados obtidos foram submetidos à análise de variância e as médias comparadas pelo teste de Tukey a $5 \%$ de probabilidade, com auxílio do programa estatístico SISVAR.

\section{RESULTADOS E DISCUSSÃO}

A aplicação de gesso em diferentes épocas na cultura do amendoim não teve efeito na produtividade de grãos e vagens, entretanto observou-se que o tratamento GPC apresentou maior número de vagens por planta e consequentemente maior número de grãos por planta do que o tratamento GP. Este resultado pode ser em função do fornecimento de Ca na camada de frutificação da cultura no momento do início da emissão dos ginóforos, garantindo adequado desenvolvimento das vagens do solo. 
16 e 17 de agosto de 2018, centro de convenções da FCAV/UNESP - Câmpus de Jaboticabal, SP

Tabela 2. Valores médios e significância dos parâmetros: produtividade de grãos e vagens, vagens por planta, grãos por planta, grãos por vagem, peso de 20 vagens, e peso de 100 grãos.

\begin{tabular}{ccccccc}
\hline Tratamentos & $\begin{array}{c}\text { Produtividade } \\
\left(\mathrm{kg} \mathrm{ha}^{-1}\right)\end{array}$ & $\begin{array}{c}\text { Vagens } \\
\text { planta }^{-1}\end{array}$ & $\begin{array}{c}\text { Grãos } \\
\text { planta }^{-1}\end{array}$ & $\begin{array}{c}\text { Grãos } \\
\text { vagem }^{-1}\end{array}$ & $\begin{array}{c}\text { Peso de } \\
\text { 20 vagens }\end{array}$ & $\begin{array}{c}\text { Peso de } \\
\text { 100 grãos }\end{array}$ \\
\hline GC & 5725 & $30,0 \mathrm{ab}$ & $55,9 \mathrm{ab}$ & 1,86 & 32,6 & 68,3 \\
GP & 5780 & $19,3 \mathrm{~b}$ & $36,4 \mathrm{~b}$ & 1,87 & 32,3 & 65,1 \\
GPC & 6285 & $34,9 \mathrm{a}$ & $65,8 \mathrm{a}$ & 1,88 & 34,9 & 71,9 \\
\hline CV \% & 6,37 & 23,11 & 22,52 & 2,63 & 9,07 & 9,07 \\
P - valor & 0,0705 & 0,0076 & 0,0063 & 0,8484 & 0,3757 & 0,2616 \\
\hline
\end{tabular}

GC - gesso aplicado em cobertura $\left(1\right.$ ton $\left.\mathrm{ha}^{-1}\right) ; \mathrm{GP}$ - gesso aplicado em pré-plantio (1 ton ha $\left.{ }^{-1}\right)$; GPC gesso aplicado em pré-plantio $\left(0,5\right.$ ton $\left.\mathrm{ha}^{-1}\right)$ e em cobertura $\left(0,5\right.$ ton $\left.\mathrm{ha}^{-1}\right)$.

Os parâmetros peso de 20 vagens e peso de 100 grãos não tiveram efeito da aplicação de gesso nas distintas épocas (Tabela 2).

Com relação ao teor de nutrientes foliar observou-se que apenas o de enxofre teve efeito da aplicação de gesso em diferentes épocas no amendoim, em que a aplicação em cobertura proporcionou as maiores concentrações (Tabela 3). $\mathrm{O}$ teor de Ca camada de 0-20 cm não teve efeito da aplicação de gesso em distintas épocas (Tabela 3), entretanto a profundidade de $20-40 \mathrm{~cm}$ houve incremento com a aplicação de gesso em pré-plantio (Tabela 3). Este resultado deve-se possivelmente pelo maior tempo para a solubilização do Ca do gesso agrícola no solo e maior exposição a ocorrência de chuvas para a percolação do nutriente no perfil do solo.

Tabela 3. Valores médios e significância dos parâmetros: Teor de $\mathrm{Ca}$ e $\mathrm{S}$ foliar, e teor de Ca nas profundidades de $0-20 \mathrm{~cm}$ e $20-40 \mathrm{~cm}$.

\begin{tabular}{|c|c|c|c|c|}
\hline \multirow{2}{*}{ Tratamentos } & $\mathrm{Ca}$ & $\mathrm{S}$ & $\mathrm{Ca}(0-20 \mathrm{~cm})$ & $\mathrm{Ca}(20-40 \mathrm{~cm})$ \\
\hline & -------- $\mathrm{g} \mathrm{kg}^{-1}$ & -------- & \multicolumn{2}{|c|}{---1----- mmolc. $\mathrm{dm}^{-3}$} \\
\hline $\mathrm{GC}$ & 13,2 & $2,56 \mathrm{a}$ & 14,4 & $10,4 \mathrm{~b}$ \\
\hline GP & 14,7 & $1,36 \mathrm{~b}$ & 18,4 & $15,4 \mathrm{a}$ \\
\hline GPC & 13,7 & $1,90 \mathrm{~b}$ & 17,0 & $12,2 \mathrm{ab}$ \\
\hline $\mathrm{CV} \%$ & 13,11 & 19,19 & 14,80 & 21,28 \\
\hline$P$ - valor & 0,4267 & 0,0010 & 0,067 & 0,036 \\
\hline
\end{tabular}

\section{CONCLUSÃO}

A aplicação de gesso agrícola em diferentes épocas não teve efeito na produtividade de grãos e vagens da cultura do amendoim. 


\section{REFERÊNCIAS BIBLIOGRÁFICAS}

BOLONHEZI, D.; GODOY, I. J.; SANTOS, R. C. Manejo cultural do amendoim. In: SANTOS, R. C. (Ed.). O Agronegócio do amendoim no Brasil. 2. Ed. Campina Grande: Embrapa Algodão, 2013. p. $185-238$.

CONAB, Acompanhamento da safra brasileira de Grãos 2015/2016. Disponível em: http://www.conab.gov.br/OlalaCMS/uploads/arquivos/16_01_12_09_00_46_boletim_graos_janeiro_2 016.pdf. Acesso em 19 de julho de 2016.

GODOY, I. J. et al. Cultivares IAC de Amendoim. Campinas: Instituto Agronômico, 2014. (IAC. Folder).

MALAVOLTA, E.; VITTI, G.C.; OLIVEIRA, S.A. Avaliação do estado nutricional das plantas: princípios e aplicações. 2.ed. Piracicaba: Potafos, 1997.

MARTINS, R. Amendoim: o mercado brasileiro no período de 2000 a 2011. In: SANTOS, R. C. (Ed.). O Agronegócio do amendoim no Brasil. 2. ed. Campina Grande: Embrapa Algodão, 2013. p. 19-44. SICHMANN, W.; NEPTUNE, A. M. L.; SABINO, N. P. Acumulação de macronutrientes pelo amendoim (Arachis hypogeae L.) cultivado em outono, época seca. Anais da Escola Superior de Agricultura “Luiz de Queiroz”, Piracicaba, v. 27, p. 393-409, 1970.

VITTI, G. C. et al. Uso do gesso em sistemas de produção agrícola. Piracicaba: GAPE, 2008. 